\title{
Design Analysis of a Security Lock System using Pass-Code and Smart-Card
}

\author{
${ }^{1}$ Omijeh, B.O and ${ }^{2}$ G.O.Ajabuego \\ ${ }^{1,2}$ Department of Electrical / Electronic Engineering, University of Port Harcourt
}

\begin{abstract}
In this work, Security Lock system using Pass code and smart card has been achieved. It is a micro controller based system which aims at interfacing selected hardware components with software to obtain a higher degree of security. In achieving this work, seven major stages were considered in the design methodology: Power supply unit, personal computer unit, micro controller unit, lock system unit, seven segment display, detector unit and alarm unit. The design specifications were strictly followed and the result obtained after construction and testing were very satisfactory. Indeed, security lock system using passcode and smartcard is a surer and safer form of security in this era of tremendous technological advancement.

Keywords: Pass-code, Smart-card, Microcontroller, Interfacing, Security Lock System.
\end{abstract}

\section{Introduction}

One of the cardinal needs of man is security of life and property. Over the centuries, access control systems were put in place to prevent access to unauthorized persons. They are called locks on doors [1]. However, locks that are operated by keys have weaknesses such as the ability to be picked. Also, there are situations of unauthorized duplication of keys, the problem that a key has to be replaced if they are found missing. Further more, theft poses a very substantial problem. It is often necessary to change door locks when it is suspected that keys may have fallen into unauthorized hands [2]. In the case of a fire hazard, when one needs to get out of the building quickly, it is not advisable to waste time searching for the key to unlock the door. Hence, in a bid to handle these shortcomings, some security devices have been introduced. For example, smartcards [3][4] are now available in banks, hotels, offices and high profile establishment but not to the general populace. Recently, the use of biometrics[5] and voice automation have been introduced.

This paper, therefore, presents the design analysis of a security lock system using pass code and smartcard with the following design objectives:

- To gain access using the right code and remain locked if the right code is not entered.

- To start an alarm when the wrong code is entered more than two times.

- To retain a high level of exclusivity within the access control region.

- To reduce the number of intruders.

- To protect against unauthorized duplication of keys that operate hardware locks.

\section{Building Blocks Of A Security Lock System}

Fig 1 shows the block diagram for the design methodology. It consists of seven stages

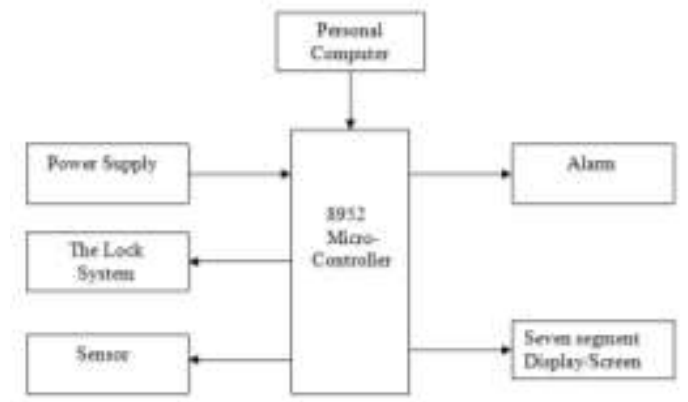

Fig 1: Block diagram of a security locks system

\section{Power Supply Unit:}

In order to operate a system or equipment there is a demand for power. The mode of application of such power will form the design of the power supply unit and its characteristic.

A $5 \mathrm{~V}$ dc Power Supply is needed to power the microcontroller and all the other modules. Also, $12 \mathrm{~V}$ dc power supply is used for operating the motor. 


\section{Personal Computer:}

The programming language used in designing the graphical user interface is visual basic. It is a terminal emulation program. It is the interface between the personal computer and the microcontroller circuit. Programs run on the microcontroller are written in assembly language. Communication between the microcontroller and the system is through serial communication technology.

There is need for a logic level converter Max232 because the logic level of the microcontroller and the serial port of the system are different. The microcontroller uses TTL standard (Transistor Transistor Logic). Logic 1 represents 5volts; and logic 0 represents 0volts. Also, the serial port of the computer uses RS 232 standard. Logic 1 represents a range of -3 to -15 volts while logic 0 represents a range of +3 to +15 volts. Hence it is the logic level converter Max232 that makes it possible for the two devices to communicate.

\section{Microcontroller}

The AT89c52 microcontroller is the brain behind the locking device. It is the meeting point for all the other units. They are all connected to it. The microcontroller inputs and outputs signals (sends and receives signal). This method is known as flow control. There are two types of flow control: software flow control, hardware flow control. In this project, we used the hardware flow control because it is the most reliable. In the hardware flow control, the microcontroller uses request to send (RTS) from the computer and clear to send (CTS) from the microprocessor (Carter, 1996; Steiner, 2006).

\section{Lock System:}

Debounce push buttons are used for the Passcode lock system. When they are pressed, the logic state changes. The microcontroller detects the change in logic state and displays the number pressed. Once six digits are pressed, the microcontroller compares these digits with the preset passcode loaded from the personal computer. If they are the same, the system opens the door (Jean, 2001).

With the card lock system, a Vero board is used to construct the smart card that has binary codes. When it is inserted into the card slot, the smart card is powered from the card slot. The system reads the binary codes which are compared with a preset binary code. If the measured code is equal to the binary code, the system is activated to open the door. If not, the card is rejected.

\section{Display unit.}

The display unit (seven segment display) is used to display information. The light emitting diode is arranged properly to make up the figures on the display .

\section{Detector Unit:}

The sensor used in this project is an infrared. It is a device capable of detecting and responding to physical stimuli such as movement, light, or heat. For the purpose of this project, the infrared detects the move of a human being The body of the human being emits the infrared rays. A change in infrared rays is detected by the infrared which causes the relay to operate. This enables the motor to move either right or left so as to open or close the door [9]

\footnotetext{
Alarm unit:

In this unit, an electronic bell is used. It is programmed to ring when the wrong code is entered more than twice. It has inbuilt speakers that enable the sound of the bell to be heard loudly.

\section{Design Analysis Security Lock System}

In the implementation of this work, certain logical steps were taken into consideration in determining the hardware components necessary. These steps followed the model of the design. Other necessary support components were identified. The detailed circuit diagram is shown in Fig.2 [10].
} 


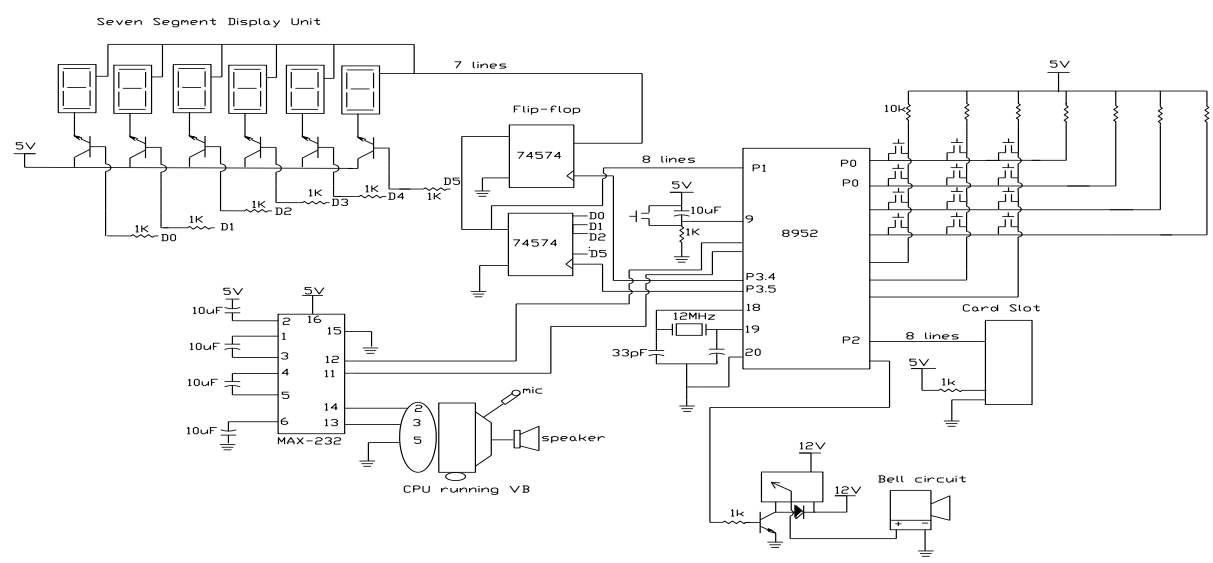

Fig 2: Detailed Circuit Diagram of Lock System

\subsection{Power Supply Unit}

The power used in this circuit is 5 volts and 12 volts dc power supply. The $5 \mathrm{~V}$ is used to operate the microcontroller and other components, while the $12 \mathrm{~V}$ is used for operating the motor.

\subsubsection{The Transformer Unit}

The transformer used in this project, is a 220 volts / 12 volts ac step - down transformer. It takes in $220 \mathrm{~V}$ ac and produces $12 \mathrm{~V}$ ac, with a load current of $300 \mathrm{~mA}$. It accomplishes this by electromagnetic induction and when the electric circuits are in mutual inductive influence of each other.

\subsubsection{Rectification}

The purpose of a rectifier is to converts ac to dc signal. The rectifier used in this work is a full wave bridge rectifier. The bridge rectifier unit is rated for a current at least as high as the transformer's secondary winding is rated for, and for a voltage at least twice as high as the RMS voltage of the transformer's output (this allows for peak voltage, plus an additional safety margin). It takes in 12 volts ac from the transformer and produces 12 volts dc. This dc has alternating current component. Thus the output is passed onto a capacitor for filtering.

\subsubsection{Power Supply Filtering}

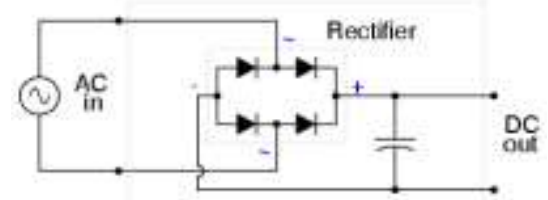

Fig 3: Schematic diagram of power supply filtering

The rectified waveforms contain ripples that have to be smoothed out in order to generate a genuine DC voltage. This we did by taking on a low-pass filter. The voltage rating of the capacitor should be greater than or equal to 1.5 the input voltage. I.e. $\mathrm{V} \geq 1.5$ (input voltage). A capacitor of $3300 \mathrm{uf} / 50 \mathrm{~V}$ was employed in this design.Fig 3.

This ensures small ripples, by making the time constant for discharging much longer than the time between re-charging. Also, a large capacitance value was considered okay, so long as its working voltage was high enough. However, for safety reasons, we chose a capacitor of 3300uf / 50V. Fig 3 and Fig 4 show the Schematic and the resultant waveforms after rectification.
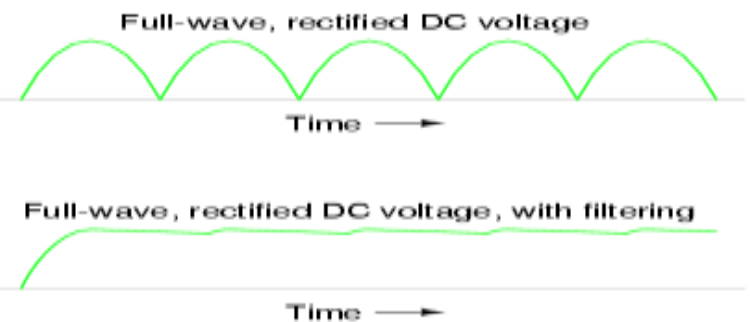

Fig 4: Waveforms after Rectification 


\subsubsection{Voltage Reference.}

7805 IC is used as a voltage regulator to bring the voltage down to 5 volts stable power source for the operation of the ICs.

\subsection{Microcontroller.}

The microcontroller used is the AT89c52, a variation of 8051 microcontroller architecture. The 8051 is the most popular microcontroller available today. Hence, it comes with a wide variety of features which makes it accessible to a wide range of applications.

The AT89c52 microcontroller has the following features:

1. 32 programmable $\mathrm{I} / \mathrm{O}$ lines.

2. 8 Kbytes ROM.

3. 256 bytes of RAM and 256 bytes of special function register.

4. On-chip oscillator and clock circuitry.

5. Universal Asynchronous Receiver / Transmitter (UART) serial port.

6. Interrupt sources.

7. Power saving operating mode.

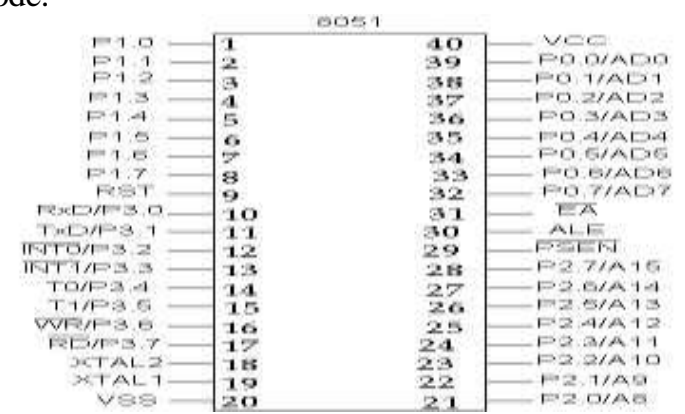

Fig 5: Pin Configuration of AT89c52

The description of the Pin Configuration of AT89c52 is as shown in Fig 5

- Vcc pin 40 : Provides supply voltage to the chip. The voltage source is $+5 \mathrm{~V}$.

- GND pin 20: is used for earthing.

- XTAL1 and XTAL2 pins 19,18: These 2 pins provide external clock

- Way 1 using a quartz crystal oscillator

- Way 2 using a TTL oscillator

- $\quad$ RST pin 9 is reset

- It is a power-on reset.

- Upon applying a high pulse to RST, the microcontroller will reset and all the values in the registers will be lost.

- /EA - pin 31 is external access: The AT89c52 microcontroller can execute a program in external memory only if EA is low. The sign " " means active low.

- For this project, /EA pin is connected to Vcc because we are not using external memory i.e. external RAM

- $\operatorname{PSEN}($ pin 29) : program store enable and $\operatorname{ALE}($ pin 30) : address latch enable are used for external ROM.

- There are four ports $\mathrm{P} 0, \mathrm{P} 1, \mathrm{P} 2$, and $\mathrm{P} 3$.

- Each port uses 8 pins. They provide the user with $32 \mathrm{I} / \mathrm{O}$ lines for connecting the microcontroller to the environs.

- All I/O pins are bi-directional.

Working Principle:

- Machine cycle

For the CPU to execute an instruction, it takes a certain number of block cycles. In the 8051 family, these block cycles are referred to as machine cycles.

The frequency of the crystal connected to the 8051 family varies from $4 \mathrm{MHz}$ to $30 \mathrm{MHz}$, depending on the chip rating and manufacturer. Very often the $11.0592 \mathrm{MHz}$ crystal oscillator is used to make the 8051-based system compatible with the serial port of the IBM PC. one machine cycle lasts for 12 oscillator periods.

- Interrupt:

An interrupt is an external or internal event that interrupts the microcontroller to inform it that a device needs its service.

\section{Steps in executing an interrupt:}

I. It finishes the instruction it is executing and serves the address of the next instruction (PC) on the stack.

II. It also saves the current status of all the interrupts internally (i.e. not on the stack) 
III. It jumps to a fixed location in memory called the interrupt vector table that holds the address of the interrupt service routine (ISR).

IV. The microcontroller gets the address of the ISR from the interrupt vector table and jumps to it. It starts to execute the interrupt service routine until it reaches the last instruction of the subroutine which is RETI (return from interrupt)

V. Upon executing the RETI instruction, the microcontroller returns to the place where it was interrupted. First, it gets the program counter (PC) address from the stack by popping the top two bytes of the stack into the PC. Then it starts to execute from that address.

\subsection{Computer Interface unit.}

The microcontroller used in this project required TTL logic levels ( 0 and 5V) for effective programming. Therefore the first step to connecting this device to the RS-232 port is to transform the RS-232 levels to 0 and 5 volts. This we did using the Max-232 level converter.

It includes a charge pump which generates +10 and $-10 \mathrm{~V}$ from a single $5 \mathrm{~V}$ supply. It also includes two receivers and two transmitters in the same package which could be handy when only transmit and receive data lines and needed.

Serial Communication: This is bit by bit transmission of data on a single line. It is different from parallel communication where each bit of the data is transmitted on different lines. When interfacing a terminal to the microcontroller, parallel communication requires a lot of pin, about 8 pins and about 3 other pins for flow control. Whereas, serial communication requires 2 pins for data transfer and if desired, 2 other pins for flow control

For this design, only 5 of the DB-9 connector pins were used.

1. Received data (RxD) pin: This pin is connected to the microcontroller's serial port transmit line

2. Transmit data (TxD) pin: This pin is connected to the receive line of the microcontroller's serial port receive line.

3. Request to Send (RTS): This pin is connected to any pin of the microcontroller. Whenever the computer wishes to send data to the microcontroller it sends a low through this line.

4. Clear to Send (CTS): This pin can be connected to any pin of the microcontroller. The microcontroller sends a low when it receives a low from RTS. The computer when it receives this signal, begins the transmission

5. Signal ground: This is connected to GND of the microcontroller circuit to create a common reference for both terminals.

\subsection{Seven Segment Display}

It is less commonly known as a seven-segment indicator. It is an assembly of light emitting diodes which can be powered individually. For the purpose of this work, Seven Segment displays are used in displaying decimal numeric feedback on the internal operations of devices. They are arranged and labeled as shown in the diagram[12]

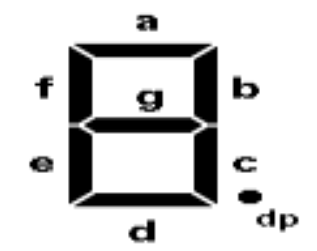

(a) Seven-Segment Display Layout

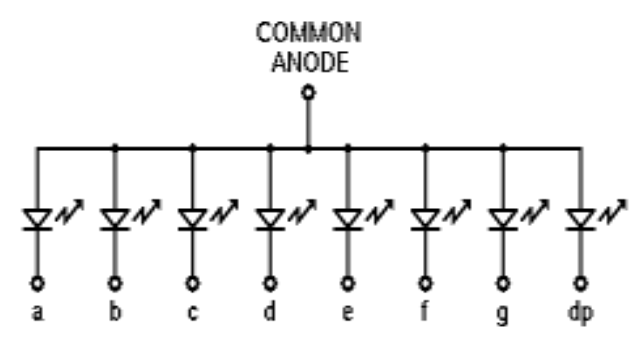

(b) Seven Segment LED Display Component.

Fig 6: Seven-Segment Display (a) Display Layout (b) LED Display Component.

Powering the entire segment will display the number 8 . Powering a, b, c, d and g will display the number 3. Numbers 0 to 9 can be displayed. The one shown is a common anode display since all anodes are joined 
together and go to the positive supply. The cathodes are connected individually to $0 \mathrm{~V}$. Resistors are placed in series with each diode to limit the current through each diode to a safe value.

\subsection{Infrared Circuitry \\ IR Transmitter:}

The current through the LED varies from 100mA to well over 1A. In order to get an acceptable control distance the LED currents are as high as possible. LED currents are high because the pulses driving the LEDs are very short. [11]

A simple transistor circuit is used to drive the LED. A transistor with a suitable HFE and switching speed was selected for this purpose. Based on Ohm's law and with the knowledge of the nominal voltage drop over an IR LED, which is approximately $1.1 \mathrm{~V}$, the resistor value used is $11 \Omega$.

\section{IR Receiver}

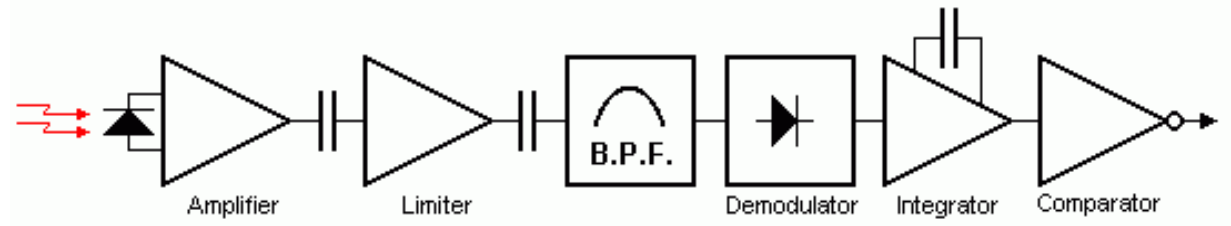

Fig 7: IR Receiver

Fig.6 is a typical block diagram of an IR receiver. Everything is built into one single electronic component. The received IR signal is picked up by the IR detection diode on the left side of the diagram. This signal is amplified and limited by the first 2 stages. The limiter acts as an AGC circuit to get a constant pulse level. Only the AC signal is sent to the Band Pass Filter. The frequency ranges from $30 \mathrm{kHz}$ to $60 \mathrm{kHz}$. Fig 7

The next stages are a detector, integrator and comparator. The purpose of these three blocks is to detect the presence of the modulation frequency. If this modulation frequency is present the output of the comparator will be pulled low.

\subsection{Clocked D Flip-Flop}

Flip flops are generally storage devices and they have one synchronous control input. 'D' stands for data. The figure below shows the symbol for a clocked D flip flop that triggers on a positive-going transition (PGT). Fig 8 shows the waveform.

The principle of operation of the D flip flop is very simple. The level present at D is stored in the flip flop at the instant the PGT occurs. The waveform in the figure below illustrates this operation. The D type flipflop has only one input (D for Data) apart from the clock. Thus, the INDETERMINATE state is avoided with this flip-flop. When the clock goes high, D (a 0 or a 1 ) is transferred to Q. When the clock goes low, Q remains unchanged. $Q$ stores the data until the clock goes high again, when new data is available

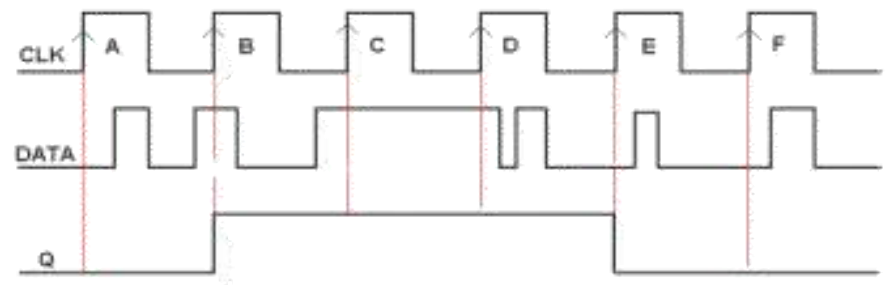

Fig 8: Waveform of Clock D Flip-Flop

Table 1: Truth table for clock D flip-flop:

\begin{tabular}{|c|c|c|}
\hline D & CLK & Q \\
\hline 0 & $\uparrow$ & 0 \\
& $\uparrow$ & 1 \\
\hline 1 & \\
\hline
\end{tabular}




\subsection{OR Gate}

Fig 9 shows the OR gate which allows the output to be true (logic 1) if any one or more of its inputs are true.

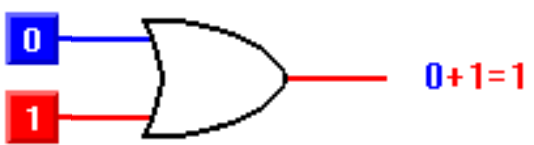

Table 2: Truth table for OR gate

Fig 9: OR gate

\begin{tabular}{|c|c|c|}
\hline A & B & Y \\
\hline 1 & $\mathrm{x}$ & 1 \\
\hline $\mathrm{x}$ & 1 & 1 \\
\hline 0 & 0 & 0 \\
\hline
\end{tabular}

3.8 Relays: Relays are electromagnetic devices that allow small electronic signals to control very large electrical signals and electronic signals. The operation of the relay depends on the voltage rating and the current rating. The voltage rating is the voltage that is applied across the terminals of the electromagnet. Current rating is the maximum current that the material can withstand. In this project, the relay rating is $12 \mathrm{Vdc}, 10 \mathrm{~A}$. Hence, the load;

$$
P=I V
$$

\subsection{Lock Section}

Password Section: Here, micro switches are used to enter the right codes which the microprocessor uses to compare the already established codes in the processor.

The shift register consists of two flip-flops connected together so that data can be transferred (shifted) along the chain from one end to the other. Calculations carried out to determine the value of the base resistors for the transistors used for the seven segment display, is as follows.

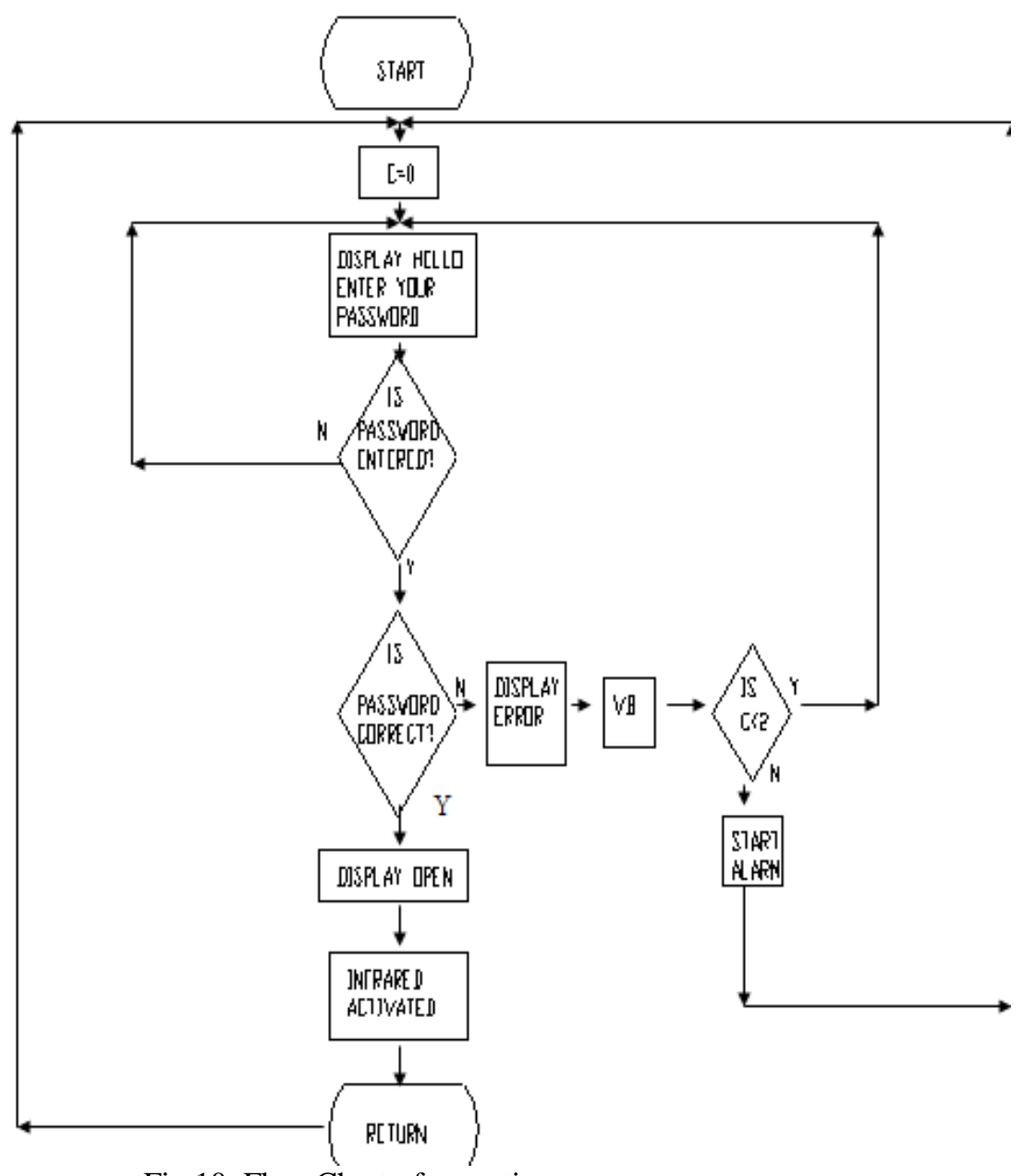

Fig 10: Flow Chart of operation process 


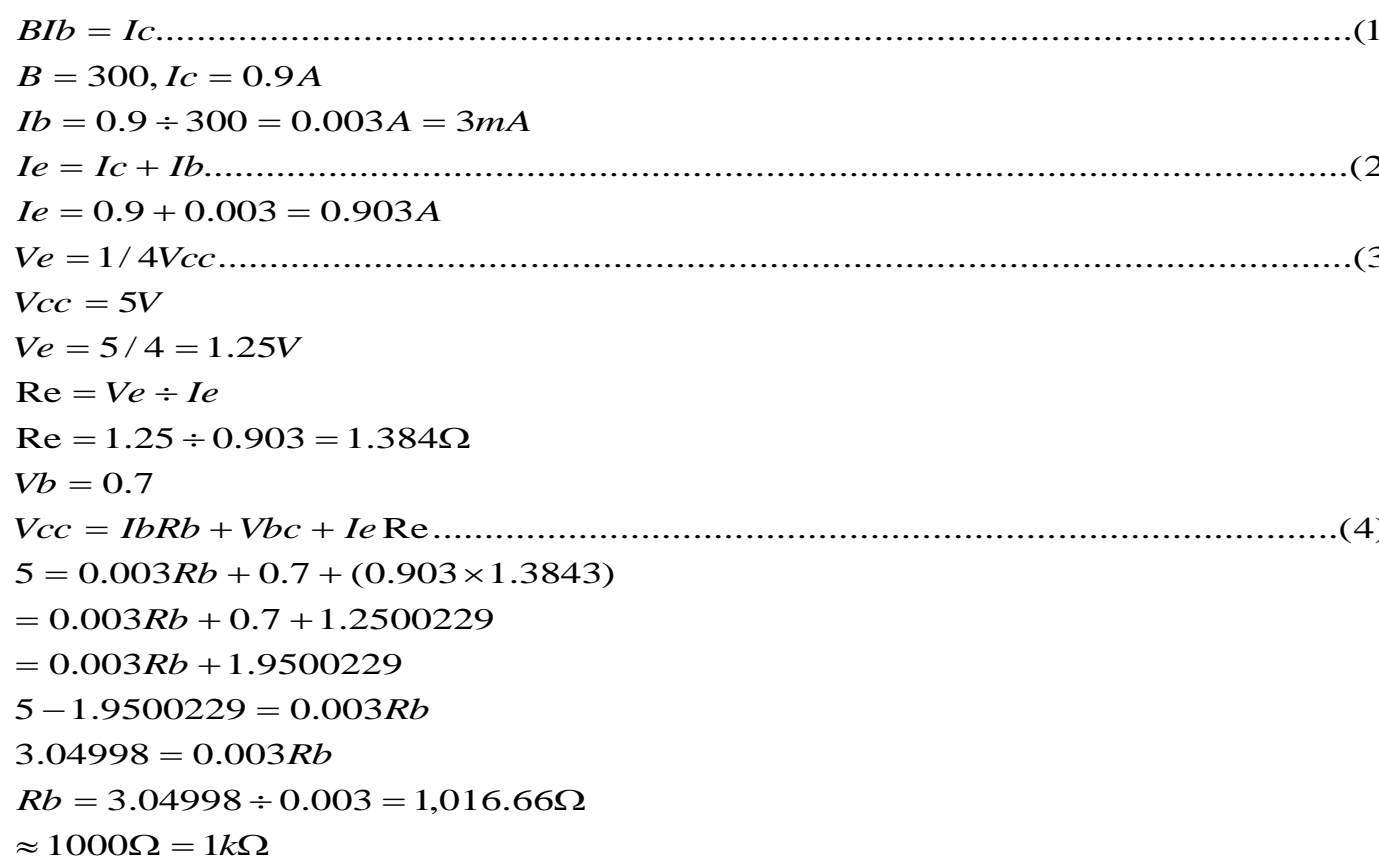

Smartcard Section: For the Card lock system, we used the following

- A Vero board of size $4.5 \times 3.7 \mathrm{~cm}$. It is used as an interface card.

- 8 bit expansion slots; this was gotten from the system board of a PC. The Vero board (interface card) communicates with the system through the extended microprocessor buses in these slots.

- Jumper wires were soldered on the Vero board for the purpose of continuity so as to have alternate 0 s and 1s e.g. 11110000 or 11111000

The features of the 8 bit expansion slots are:

- 8 bit bidirectional data bus,

- 20 address lines for the IO channel.

- 6 interrupts channels

- Control signals for memory and IO read or write operations,

- Clock and timing signals and

- Three channels of DMA control lines.

\section{Software Design}

Fig 10 shows the Flow Chart used for the software design.

\section{Results And Discussion}

The test results in Table 3 shows good response time and performance to design specifications.

Table 3: Testing and Results

\begin{tabular}{|l|l|l|l|}
\hline Check & Action & Result & Comments \\
\hline & $\begin{array}{l}\text { On the VB interface, click } \\
\text { on password and then type } \\
\text { in the required code that is } \\
\text { to be compared and press } \\
\text { LOAD }\end{array}$ & Please enter your code. & $\begin{array}{l}\text { This activates the system } \\
\text { to start accepting security } \\
\text { code. }\end{array}$ \\
\hline $\begin{array}{l}\text { Blinking of Red } \\
\text { LED's }\end{array}$ & $\begin{array}{l}\text { Type in the expected code } \\
\text { on the device and press } \\
\text { enter }\end{array}$ & $\begin{array}{l}\text { Seven segment display } \\
\text { will show open if correct } \\
\text { code is entered. }\end{array}$ & $\begin{array}{l}\text { The expected code is } \\
\text { compared with the } \\
\text { required code and if they } \\
\text { match, the door will open } \\
\text { automatically. }\end{array}$ \\
\hline $\begin{array}{l}\text { Door opens and } \\
\text { remains open } \\
\text { for about 19secs }\end{array}$ & Key in the wrong code & The display shows error. & $\begin{array}{l}\text { If RED LED indication } \\
\text { entered code is not valid } \\
\text { then process stops. Try } \\
\text { entering the code again. }\end{array}$ \\
\hline
\end{tabular}




\begin{tabular}{|l|l|l|l|}
\hline $\begin{array}{l}\text { Door will not } \\
\text { open }\end{array}$ & $\begin{array}{l}\text { Enter code more than } 3 \\
\text { times }\end{array}$ & $\begin{array}{l}\text { Alarm comes on for 14 } \\
\text { secs. }\end{array}$ & $\begin{array}{l}\text { Purpose of the alarm is to } \\
\text { stop an intruder from } \\
\text { trying different } \\
\text { combinations in an } \\
\text { attempt to break in or gain } \\
\text { access. }\end{array}$ \\
\hline & $\begin{array}{l}\text { On the VB interface, click } \\
\text { on smart card and then type } \\
\text { in the required code that is } \\
\text { to be compared and press } \\
\text { LOAD }\end{array}$ & $\begin{array}{l}\text { Please enter your smart } \\
\text { card. }\end{array}$ & $\begin{array}{l}\text { This activates the system } \\
\text { to start accepting smart } \\
\text { cards. }\end{array}$ \\
\hline $\begin{array}{l}\text { Blinking of Red } \\
\text { LED's }\end{array}$ & $\begin{array}{l}\text { Insert the expected smart } \\
\text { card into the slot. }\end{array}$ & $\begin{array}{l}\text { Seven segment display } \\
\text { will show open if correct } \\
\text { smartcard is inserted }\end{array}$ & $\begin{array}{l}\text { The expected code on the } \\
\text { smartcard is compared } \\
\text { with the required code and } \\
\text { if they match, the door } \\
\text { will open automatically. }\end{array}$ \\
\hline $\begin{array}{l}\text { Door opens and } \\
\text { remains open } \\
\text { for about 19secs }\end{array}$ & $\begin{array}{l}\text { Insert the wrong smartcard. } \\
\text { of }\end{array}$ & The display shows error. & $\begin{array}{l}\text { If RED LED indication } \\
\text { entered code is not valid } \\
\text { then process stops and } \\
\text { door will not open. }\end{array}$ \\
\hline
\end{tabular}

\section{Conclusion}

A Security lock system using Pass-codes and Smart-card has been designed, analyzed and implemented. Its advantages cannot be over-emphasized in these modern days of technological breakthroughs. The addition of a PC interface enables flexibility in terms of manipulating the different combinations of pass codes and smart card. Security lock system using Pass-codes and Smart-card would be found very useful in applications which require strong security protection and authentication such as: Banks, Industrial Facilities, Commercial Buildings, Airports, Museums and Fine Art, Warehouses e.t.c.

\section{Reference:}

[1] Bellis M. (1972); "The history of locks" www.About.com $\left(28^{\text {th }}\right.$ March, 2007)

[2] Abraham.D.G, GM Dolan, GP Double, JV Stevens (1991) “Transaction Security System", in IBM Systems Journal v 30 no 2 (1991) pp 206-229

[3] Reid, J. \& Looi, M., Making Sense of Smart Card Security Certifications, Fourth Working Conference on Smart Card Research and Advanced Applications, 20-22.9.2000, Bristol, UK.

[4] Ranke.W and Efing. W (2000): Smart card hand book, $2^{\text {nd }}$ Edition, New York, John Wiley AND Sons

[5] Bovenlander. E \& Van Renesse,(1995) "Smartcards and Biometrics: An Overview", in Computer Fraud and Security Bulletin (Dec 95) pp 8-12

[6] Carter .J (1996): Microprocessor Architecture and Microprogramming - A State-Machine Approach, Prentice-Hall, 1996.

[7] Steiner C. (2006); "8052 Instruction set" www.8052.com. (18 ${ }^{\text {th }}$ April, 2007).

[8] Jean-Jacques Quisquater and David Samyde (2001): ElectroMagnetic Analysis (EMA): Measures and Couter-Measures for Smard Cards. In Smart Card Programming and Security (E-smart 2001), Cannes, France, LNCS 2140, pp.200-210. September 2001.

[9] Schneize.B, A. Shostack, "Breaking Up Is Hard To Do: Modeling Security Threats for Smart Cards", USENIX Workshop on Smartcard Technology, Chicago, Illinois, USA, May 10-11, 199

[10] Kelly B. (1995); "IR Transmitter and Receiver" www.ask.com. (28 ${ }^{\text {th }}$ April, 2007)

[11] Odia.A (2006) - Design and Construction of a Security Lock System using Pass-Code, Smart-Card, voice Technology, Department of Electrical/Electronic Engineering, University of Port Harcourt, Port Harcourt, 2007

[12] Tocci J.,"Digital Systems Principles and Applications”, Prentice-Hall Publishers., India, 2004, p.511 